\title{
Changes to the TODS Editorial Board
}

\author{
Christian S. Jensen \\ csj@cs.aau.dk
}

\begin{abstract}
It is of paramount importance for a scholarly journal such as ACM Transactions on Database Systems to have a strong editorial board of respected, world-class scholars. The editorial board plays a fundamental role in attracting the best submissions, in ensuring insightful and timely handling of submissions, in maintaining the high technical standards of the journal, and in maintaining the reputation of the journal. Indeed, the journal's Associate Editors, along with the reviewers and authors they work with, are the primary reason that TODS is a world-class journal.
\end{abstract}

\section{Retiring Associate Editors}

As of January 1, 2016, five Associate Editors have ended their terms:

- Wenfei Fan

- Chris Jermaine

- Tova Milo

- Lucian Popa

- Divesh Srivastava

They have served on the editorial board for six, or between six and seven, years. In addition, they will stay on until they complete their current loads. They have each provided very substantial high-caliber service to the journal and the database community. Specifically, I have never seen them compromise on quality when handling submissions, and I believe that they have uniformly made sound technical decisions. We are all fortunate that they have donated their time and unique expertise during these years.

\section{New Associate Editors}

Also as of January 1, 2016, five new Associate Editors have joined the editorial board:

- Marcelo Arenas (http: //web.ing.puc.cl/ marenas)

- Gao Cong (http: / / www . ntu. edu.sg/home/ gaocong/)

- Torsten Grust (http://db. inf.unituebingen.de/team/grust)

- Peter Haas (http://researcher.watson. i.bm.com/researcher/view.php? person=us-phaas)

- Wim Martens (http://www. theoinf unibayreuth.de/en/team/Martens_Wim/)

All five are highly regarded scholars in the field of database systems. We are very fortunate that these outstanding scholars are willing to volunteer their valuable time and indispensable expertise for handling manuscripts for the benefit of our scientific community. Indeed, I am gratified that they have committed to help TODS continue to evolve and improve, and I am looking forward to working with them. 